\title{
Kinetics biodegradation of triazophos by Klebsiella oxytoca TDB-1
}

\author{
Xinghua Li ${ }^{1}$, Lei Ren ${ }^{1}$, Deyong Zhang ${ }^{1,2}$, Yong Liu ${ }^{1,2,3 \star}$, Songbai Zhang ${ }^{2}$, Xiangwen Luo ${ }^{2,3}$, \\ Ju'e Cheng $^{2,3}$ and Jing Peng ${ }^{2,3}$
}

\author{
${ }^{1}$ Branch of Longping, Graduate College, Central South University, Changsha, China. \\ ${ }^{2}$ Key laboratory of pest management of horticultural crop of Hunan province, Hunan Plant Protection Institute, Changsha, \\ China. \\ ${ }^{3}$ Hunan Agriculture University, Changsha, China.
}

Accepted 29 November, 2012

\begin{abstract}
A triazophos (TAP)-degrading bacterial strain, Klebsiella oxytoca TDB-1, which could use TAP as sole carbon source, was isolated by enrichment culture technology. The growth characteristics of strain TDB-1 with pressure of TAP were tested, and the results show that optimum growth condition was at $30{ }^{\circ} \mathrm{C}, \mathrm{pH} 8$ and $2 \%(\mathrm{v} / \mathrm{v})$ inoculation. Strain TDB-1 was great promise in TAP biodegradation for extreme $\mathrm{pH}$ tolerance (pH 4 and 10). The kinetic of strain TDB-1 in degrading TAP followed first-order model under optimal growth conditions. Cell surface hydrophobicity (CSH) assays of strain TDB-1 reflected that the strain TDB-1 was of higher hydrophobicity while grown on higher concentration of TAP. The growth and TAP-biodegradation characteristics of strain TDB-1 revealed that it would be an excellent alternative degrader for bioremediation of TAP contaminants, especially for that with extreme $\mathrm{pH}$, such as some industrial wastewaters.
\end{abstract}

Key words: Biodegradation, triazophos, Klebsiella oxytoca TDB-1, cell surface hydrophobicity.

\section{INTRODUCTION}

Organophosphorus pesticides (OPs) were poured into agricultural producing since the late 1970s, for the merits of high insecticidal activity and broad-spectrum (Kaloyanova and El-Batawi, 1991). The widespread use has caused severe environmental pollution since OPs applied in agricultural areas do not remain at their target sites, but often enter aquatic environments via soil percolation, air drift or surface run-off (Rovedatti et al., 2001; Anderson et al., 2003; Sawaya et al., 2000). The potential threat of OPs to the environment and to public health is proved by empirical analysis and experiment verification (Hayes et al., 1980). OPs are poisoning to peripheral and central nervous system, resulting in symptoms termed "organophosphorus induced delayed neuropathy" (Jokanović and Kosanović, 2010; Mearns et

${ }^{*}$ Corresponding author. E-mail: haoasliu@163.com or zsongb@hotmail.com (Songbai Zhang). Tel: +86 73186491736. Fax: +86 73184691166 . al., 1994). Therefore, several species of OPs, such as parathion-methyl, moncrotophos,parathion, and so on were forbidden because of highly toxic to non-target organisms and mammal (Hreljac and Filipič, 2009).

Triazophos [0,0-diethyl-o-(1-phenyl-1,2,4-triazol-3-yl) thiophosphate] (TAP), one of alternatives to high-toxic OPs, has been widely used on main staple food crops (maize, rice) and vegetables since the late 1970s. It was reported that the mean half-life of triazophos in wheat plants (grain, stems, and leaves) was 5.22 days with a dissipation rate of $90 \%$ over 14 days, and the half-life in soil was 7.93 days with a dissipation rate of $90 \%$ over 21 days (Li et al., 2008). However, TAP-contamination of the environment could also not be ignored. TAP-contamination of the environment is accumulating and high level of TAP residue has been found in a wide variety of foods according to several US and European food monitoring schemes (Alexis et al., 2001). TAP is highly toxic to most fishes, except shellfishes (Lin and Yuan, 2005). In China, TAP has also been utilized as fungicide in intertidal aquiculture in farming shellfish such 
as Sinonovacula constricta and Tegillarca granosa (Lin and Yuan, 2005). The potential threat of coastal waters pollution by TAP is raising concern for the misuse of it in intertidal aquiculture, in recent years; fish kill accidences sporadically took place in coastal areas of Southern of China, mainly because of TAP contamination

Bioremediation of OPs is recognized as economical and reliable methods. In recent decades, the microbial degradation of OPs has been intensively studied, especially in high-toxic and high-residual OPs, such as parathion and methyl parathion. Several degradation bacteria, including strains in genus Enterobacter (Concepción et al., 2012), Arthrobacter, Burkholderia, Sinorhizobium and Mycobacterium (Seo et al., 2007), Serratia and Pseudomonas (Cycoń et al., 2009), and so on were isolated. Stimulating further studies demonstrated that all of them degrade OPs by hydrolase such as opd gene coding enzyme (Concepción et al., 2012; Steven et al., 2008). Nevertheless, some high-toxic and high-residual species of OPs, but not limited to parathion and methyl parathion, have been banned for use in agriculture in recent years. Many mid-toxic and low-residual Ops such as TAP, were widely utilized as alternative. Little studies have been published on the microbial degradation of TAP, although, Wang et al. (2005) isolated a TAP degrading bacterial strain, to their best knowledge, that was the first report of the microbiological degradation of TAP.

The cell surface hydrophobicity (CSH) is believed as one of the representation factors of degradation capacity of organisms, because the first step in the process of biodegradation is adhesion of the pollutants to cell surfaces of the organisms (Rosenberg et al., 1980). Bastiaens et al. (2000) reported that hydrophobicity is positively correlated to degradation efficiency of polycyclic aromatic hydrocarbon.

The objective of this study centered on the isolation, identification and degrading characteristics of TAP in situ. The study also involved the investigation of cell surface hydrophobicity property during the degrading progress.

\section{MATERIALS AND METHODS}

\section{Chemicals and media}

Sample of TAP (95.0\% pure analytical grade) were kind gift from $\mathrm{Dr}$ Xingan Liu (Institute of Plant Protection of Chinese Academy of Agricultural Science). The standard samples of TAP $(99.0 \%$ pure analytical grade) were provided by the Tianjing orient green technology Co., Ltd (Jiangshu province, China). TAP was dissolved in acetone as a stock solution ( $50 \mathrm{~g} / \mathrm{l})$. Medium for enrichment (EM) contained $10 \mathrm{~g}$ peptone, $1.0 \mathrm{~g}$ glucose, $1.0 \mathrm{~g} \mathrm{NaCl}$, and $1.0 \mathrm{~g}$ $\mathrm{KH}_{2} \mathrm{PO}_{4}$ in $1 \mathrm{~L}$ of deionized water. Medium for isolation (IM)

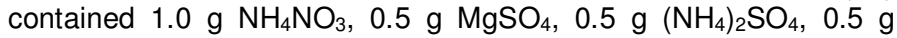
$\mathrm{KH}_{2} \mathrm{PO}_{4}, 0.5 \mathrm{~g} \mathrm{NaCl}$, and $1.5 \mathrm{~g} \mathrm{~K}_{2} \mathrm{HPO}_{4}$ in $1 \mathrm{~L}$ of deionized water.

In order to investigate whether isolates can use TAP as the sole carbon source, the TAP stock solution was added to IM medium at a final concentration of $50 \mathrm{mg} / \mathrm{l}$. The solid medium contained $2 \%$ agar. The $\mathrm{pH}$ of all media was adjusted to 7.2 to 7.4 with $10 \mathrm{M} \mathrm{NaOH}$ or 2
$\mathrm{M} \mathrm{HCl}$. All other chemicals were of analytical grade and obtained from Shanghai Sango Biological Engineering Techonology and Services Co., Ltd (Shanghai, China). The soil (100 g) was sampled from the top layer $(0$ to10 cm) at rice field in Changsha, Hunan, China. This field has utilized OPs for pest prevention over 5 years.

\section{Enrichment and isolation of TAP-degrading strain TDB-1}

Soil samples $(10.0 \mathrm{~g})$ were added to EM medium containing $50 \mathrm{mg} / \mathrm{l}$ TAP and incubated at $30^{\circ} \mathrm{C}$ in a rotary shaker at $180 \mathrm{rpm} .10 \mathrm{ml}$ of the culture broth was transferred daily to $90 \mathrm{ml}$ of fresh EM medium, while its TAP concentration increased doubly. After the fourth enrichment transfer, each culture $(10 \mathrm{ml})$ was centrifuged to get the pellets and was used to inoculate the corresponding plates of EM solid medium with TAP $(100 \mathrm{mg} / \mathrm{l})$ and incubated at $30^{\circ} \mathrm{C}$ until visible growth appeared. The biggest colony in plate was selected and named TDB-1. Strain TDB-1 was pre-cultured in EM medium and monitored by diluted plate method. The starting number of cells for the following tests was adjusted to approximate $2 \times 10^{9}$ cfu (colony forming unit) $/ \mathrm{ml}$.

\section{Identification of TAP-degrading strain TDB-1}

Strain TDB-1 was identified based on its morphological, physical and biochemical properties according to Bergey's Manual of Determinative Bacteriology (George et al., 1994). The genomic DNA was extracted as described previously (Seo et al., 2007) and 16S rDNA gene was amplified using polymerase chain reaction (PCR) with primer 27F (5`-AGAGTTTGATCCTGGCTCAG-3`) and 1492R (5`-GGTTACCTTGTTACGACTT-3`). The PCR products were purified and sequenced by BGI Life Tech Co., Ltd. The homology was analyzed by BLAST in GenBank (http://blast.ncbi.nlm.nih.gov/). Phylogenetic relationships were analyzed by the evolutionary distance matrix calculated by the neighbor-joining method and a neighbor-joining tree was constructed using MEGA5.0 (Tamura et al., 2011).

\section{Effect of different factors on the growth of strain TDB-1 under TAP pressure}

Factors affecting growth of strain TDB-1 under TAP pressure such as TAP concentration ( 50 to $500 \mathrm{mg} / \mathrm{l}$ ), $\mathrm{pH}$ (4 to 10$)$, temperature (5 to $\left.45^{\circ} \mathrm{C}\right)$ and initial inoculation $(0.5$ to $8 \%(v / v))$ were investigated. To determine the effect of TAP concentration on strain TDB-1 growth, strain TDB-1 was grown in IM medium with different initial TAP concentration. The $\mathrm{pH}$ optimum experiments for strain TDB-1 growth were performed in different $\mathrm{pH}$ IM medium with TAP concentration of $100 \mathrm{mg} / \mathrm{l}$. The temperature experiments for strain TDB-1 growth were performed when it was grown in IM medium with TAP concentration of $100 \mathrm{mg} / \mathrm{l}$ and cultured in different temperature. For evaluating inoculation on strain TDB-1 growth, the different initial inoculation was added in IM medium with TAP concentration of $100 \mathrm{mg} / \mathrm{l}$. All of tests were in triplicate and incubated at $180 \mathrm{rpm} .2$ $\mathrm{ml}$ of broth of each sample was measured spectrophotometricly at $\mathrm{OD}_{600}$ at regular interval.

\section{Determination of TAP degrading activity}

The TAP degradation rate was determined by investigating the yield of the $p$-nitrophenol with the method mentioned previously (Yang et al., 2008). A standard curve of the relationship between the absorbance in $405 \mathrm{~nm}$ and the concentration of $p$-nitrophenol was established (the $R^{2}$ of the curve is 0.9916 that means the relationship is creditable, data not shown). 


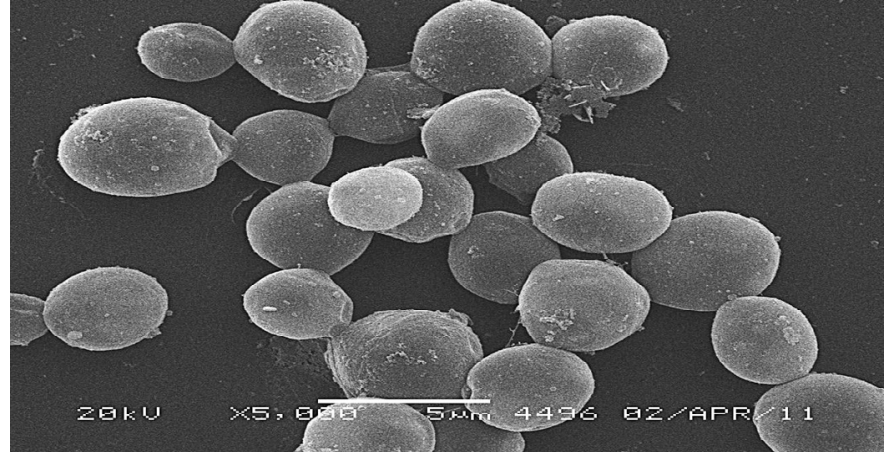

Figure 1. Scanning electron micrograph of strain TDB-1 $(\times 5,000)$.

To study the degradation kinetics of TAP by strain TDB-1, first-order model (Equation 1) was used (Cycoń et al., 2009).

$$
\mathrm{C}_{\mathrm{t}} / \mathrm{C}_{0}=\mathrm{e}^{-\mathrm{kt}}
$$

Where, $\mathrm{C}_{0}$ is the concentration of TAP at the initial time, $\mathrm{C}_{t}$ is the concentration of TAP at time $t$ and the $t$ is the degradation period in minutes. The degradation rate constant (k) was determined by measuring the $\mathrm{C}_{0}$ and $\mathrm{C}_{\text {. }}$.

The half-life $\left(\mathrm{t}_{1 / 2}\right)$ of TAP was determined using the algorithm as expressed in Equation (2).

$$
t_{1 / 2}=(\ln 2) / k
$$

Where, $\mathrm{k}$ is the rate constant $\left(\min ^{-1}\right)$.

\section{Measurement of the relative $\mathrm{CSH}$}

The relative CSH of strain TDB-1 in TAP biodegradation was tested by a modified microbial adherence to hydrocarbon (MATH) methods (Zhang et al., 2009; Canganella et al., 2011) with slight modifications. Briefly, $3 \mathrm{ml}$ of broth was harvested by centrifugation $(4,000 \mathrm{rpm}, 10$ min, $\left.4^{\circ} \mathrm{C}\right)$, washed twice with $50 \mathrm{mmo} / \mathrm{l}$ phosphate buffer $(22.2 \mathrm{~g}$ $\mathrm{K}_{2} \mathrm{HPO}_{4} \cdot 3 \mathrm{H}_{2} \mathrm{O}, 7.26 \mathrm{~g} \mathrm{KH}_{2} \mathrm{PO}_{4}$ per liter of deionized water, $\mathrm{pH} 7.0$ ), and resuspended with the same buffer to give a final concentration of cells of approximately $O D_{600}$ value at 0.6 . Aliquots of the suspension was added to glass tubes and overlaid with $1 \mathrm{ml}$ of $p$-xylene. The resultant aqueous/organic mixtures were mixed by vortexing for $2 \mathrm{~min}$. After equilibration for $40 \mathrm{~min}$, the contaminating xylene was removed by bubbling air $(2 \mathrm{ml} / \mathrm{s})$. The lower aqueous phase was then carefully removed and its absorbance at $600 \mathrm{~nm}$ was measured. The $\mathrm{CSH}$ value was calculated as the percentage of the decrease in absorbance of the aqueous phase before and after mixing with $p$-xylene, using the following equation: $\mathrm{CSH}(\%)=100 \times$ $\left(A_{i}-A_{\mathrm{f}}\right) / A_{i}$; where, $A_{\mathrm{i}}$, is the initial optical densities at $600 \mathrm{~nm}$ of the aqueous phase; $A_{\mathrm{f}}$ is the final optical densities at $600 \mathrm{~nm}$ of the aqueous phase.

\section{RESULTS AND DISCUSSION}

\section{Isolation and identification of degradation strain TDB-1}

Strain TDB-1 was sphere (Figure 1) and Gram negative
$\left(\mathrm{G}^{-}\right)$and it was positive for indole production, citrate utilization, reduction of nitrate, Voges-Proskauer test and methyl red test. The 16S rDNA sequence of strain TDB-1 was $1505 \mathrm{bp}$ and was deposited in the GenBank (accession number: JQ068819), and has the highest similarity to that of the reference sequence of Klebsiella oxytoca (AB353046) and was in the same cluster by phylogenetic analysis (Figure 2). Based on these observations, the isolate was tentatively identified as $K$. oxytoca. Several bacterial strain for degrading OPs (including TAP) were isolated (Lin and Yuan, 2005; Zhang et al., 2002; Concepción et al., 2012), and as far as our knowledge, they did not include strain of $K$. oxytoca.

\section{Effect of different factors on growth of strain TDB-1 under TAP pressure}

The growth of bacteria was effected by different factors such as $\mathrm{pH}$, temperature, initial pollutant concentration and initial inoculation, and biomass has a positive relation to biodegradation (Zhang et al., 2009). It is necessary to understand the effects of these factors to growth of strain TDB-1, to design efficient conditions to enhance TAP degradation.

As shown in Figure 3a, strain TDB-1 grow well from 25 to $35^{\circ} \mathrm{C}$ and the optimal temperature was $35^{\circ} \mathrm{C}$. The comparative low and high temperature $\left(<15^{\circ} \mathrm{C}\right.$ and $>$ $45^{\circ} \mathrm{C}$ ) almost completely inhibited the growth of strain TDB-1.

The excellent tolerance of strain TDB-1 to $\mathrm{pH}$ is indicated in Figure 3b. The growth of strain TDB-1 was scarely inhibited from $\mathrm{pH} 5.0$ to 9.0 , and optimal $\mathrm{pH}$ was 7.0. Interestingly, even in extreme $\mathrm{pH}$ value of 4.0 and 10.0 , only about $3 \mathrm{~h}$ delay of entering logarithmic phase was displayed. Although many bacterial strain are well tolerant to $\mathrm{pH}$, but some strains of acidophile or alkaliphile, cannot commonly degrade pollutants (Canganella et al., 2011). This result implies that strain TDB-1 is extraordinary potential for TAP bioremediation in extreme $\mathrm{pH}$ environment.

The effects of different initial concentration of TAP on growth were measured and the results are shown in Figure 3c. The growth of strain TDB-1 was inhibited as much as the initial TAP concentration increased. Strain TDB-1 showed the highest growth activity under $100 \mathrm{mg} / \mathrm{l}$ of TAP concentration. This result was consistent with previous study (Cycoń et al., 2009; Wang et al., 2005), which reveal that the toxicity of OPs and its metabolites was depended on its concentration.

The results of the initial inoculation (Figure $3 d$ ) indicated that more rapid growth was displayed as initial inoculation increased. Previous study indicated that inoculation is an important factor that determines growth, and the efficiency of degradation of target pesticides was dependent on the biomass, as a higher inoculation could compensate for the initial population decline and so enhanced the degradation (Cycoń et al., 2009). Figure 3d also shows 


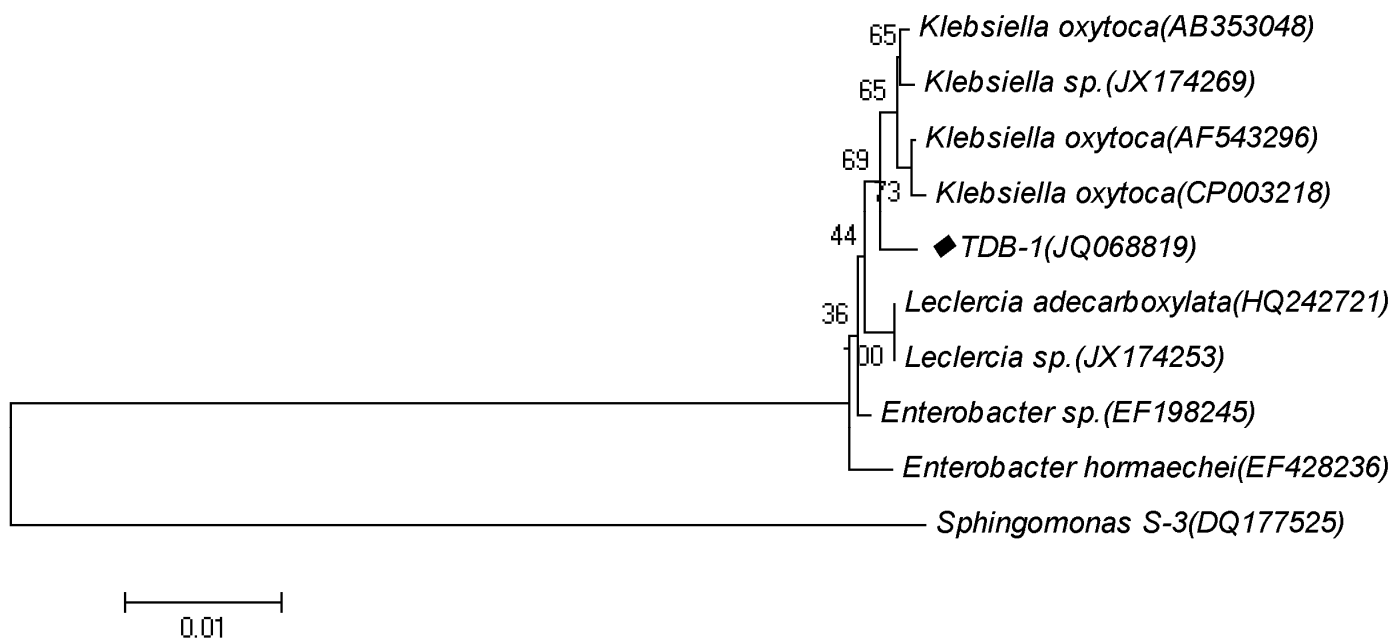

Figure 2. The phylogenetic tree of strain TDB-1 based on 16S rDNA gene sequence analysis, Sphingomonas S-3 was selected as the out group to root tree.

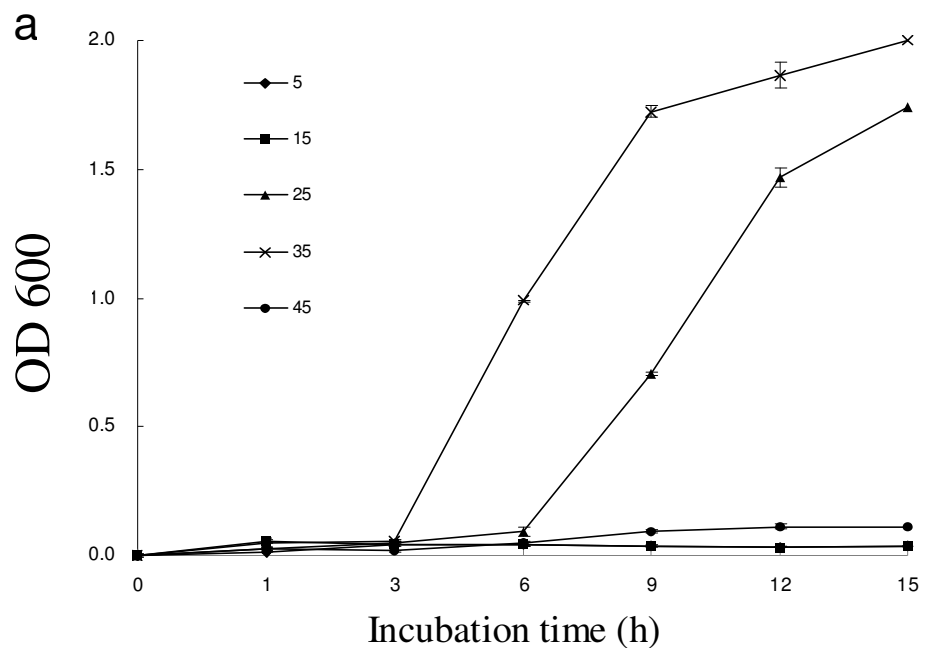

b

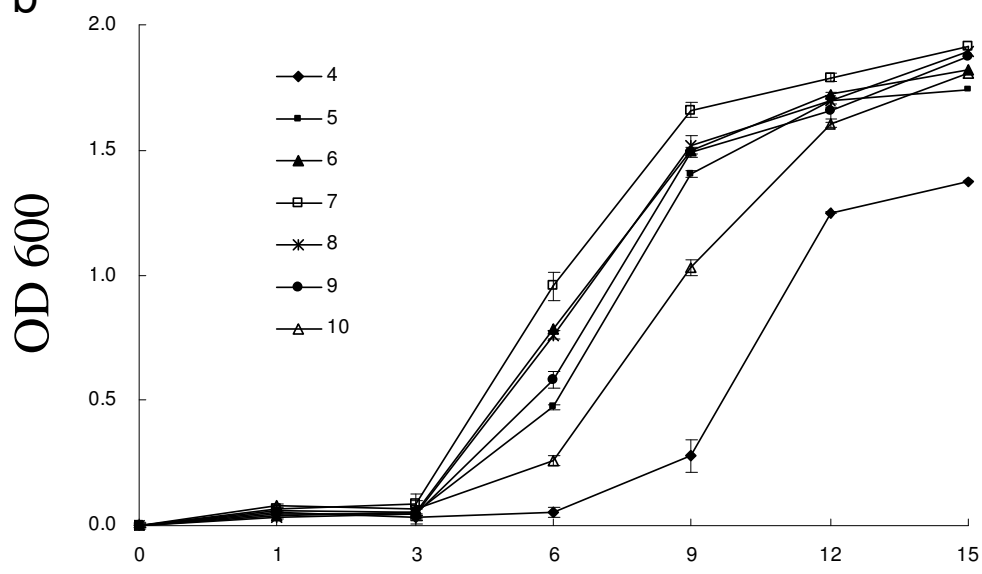

Incubation time $(\mathrm{h})$

Figure 3. Effect of different factors on growth of strain TDB-1. (a) Temperature $\left({ }^{\circ} \mathrm{C}\right)$; (b) $\mathrm{pH}$; 
Figure 3. Contd

C
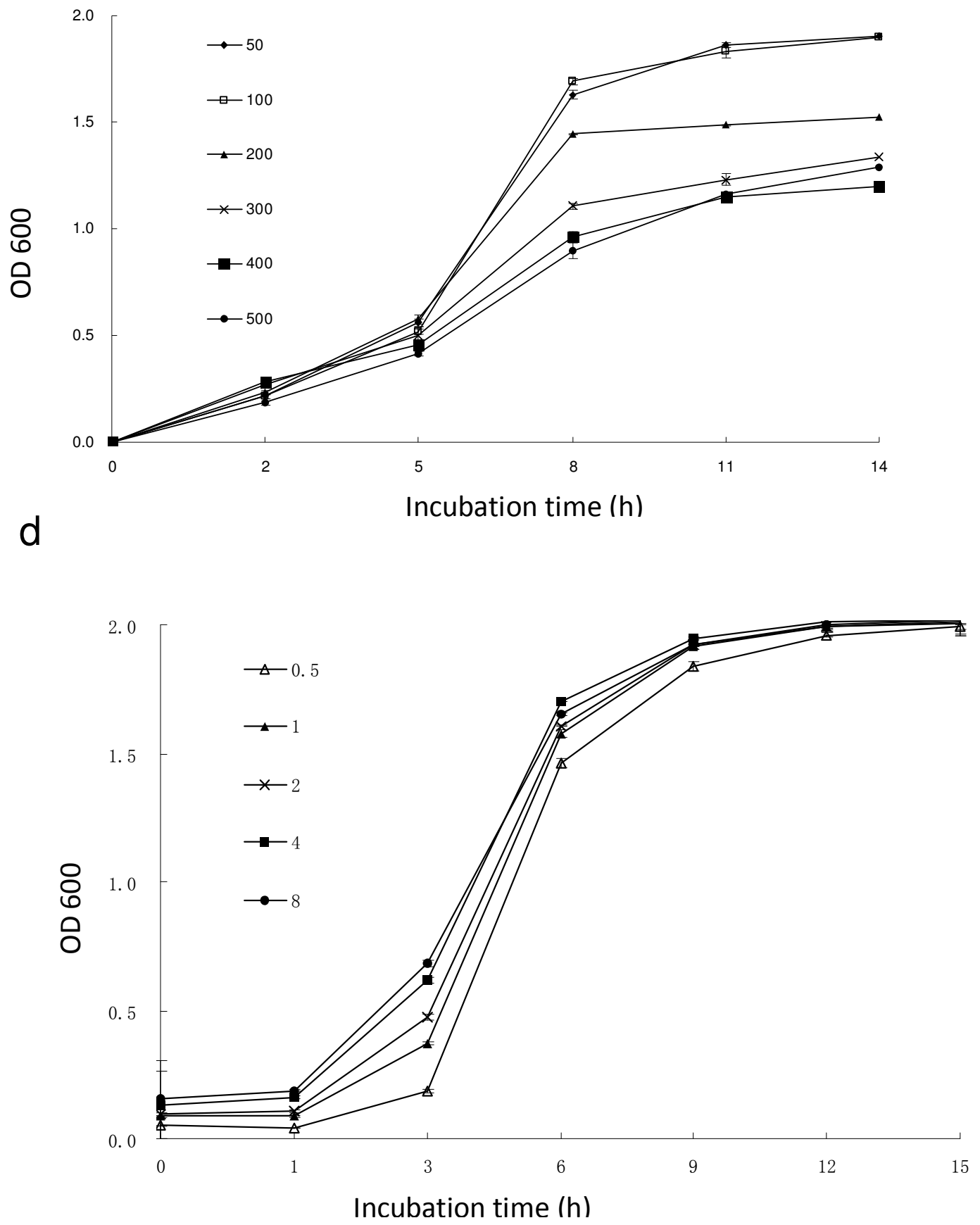

Figure 3. Effect of different factors on growth of strain TDB-1.(c) initial TAP concentration $(\mathrm{mg} / \mathrm{l})$ and $(\mathrm{d})$ Inoculation $(\mathrm{v} / \mathrm{v})$.

that there was no obvious difference in biomass $\left(\mathrm{OD}_{600}\right)$ in inoculation over $2 \%(\mathrm{v} / \mathrm{v})$, indicating that higher inoculation limited growth, probably because of shortage of nutrient and mutual competition of the organisms themselves (Chen et al., 2011). The optimal inoculation was $2 \%(v / v)$. 


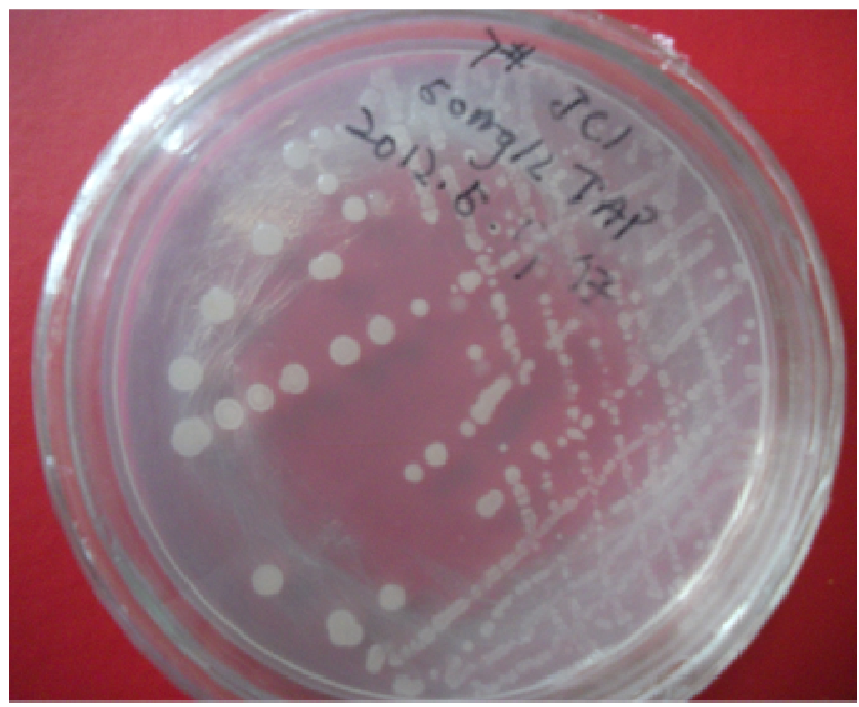

Figure 4. Strain TDB-1 growth in plate using $100 \mathrm{mg} / \mathrm{l}$ of TAP as sole carbon.

Table 1. Kinetic parameters of TAP degradation by strainTDB-1

\begin{tabular}{lccc}
\hline Treatment $(\min )$ & $\mathrm{K}\left(\mathbf{m i n}^{-1}\right)$ & $\mathbf{t}_{1 / 2}(\min )$ & $\boldsymbol{R}^{2}$ \\
\hline CK & 0.00141 & 491.5937 & 0.9415 \\
Strain TDB-1 & 0.06757 & 10.2582 & 0.9212 \\
\hline
\end{tabular}

\section{Determination of TAP degrading activity}

Strain TDB-1 could utilize TAP as sole carbon, because of its growth on IM medium (remove carbon source); using $50 \mathrm{mg} / \mathrm{l}$ of TAP as sole carbon (Figure 4). This result shows that TAP of strain TDB-1, has detoxifying capacity and further study of gene(s) of detoxification enzyme(s) to show the detoxification mechanism of TAP should be done.

Strain TDB-1 would be capable of utilizing TAP as sole carbon (data not shown), which shows its potential in TAP bioremediation. The validation of the first-order kinetics was tested and is shown in Table 1. The TAP degradation process by strains TDB- 1 was characterized and $k$ and $t_{1 / 2}$ was 0.06757 and $10.2582 \mathrm{~min}$, respectively. A non-inoculated control showed that the $k$ and $t_{1 / 2}$ was 0.00141 and $491.5937 \mathrm{~h}$ (Table 1). This result shows that strain TDB-1 could efficiently degrade TAP.

\section{Measurement of the relative $\mathrm{CSH}$}

The CSH of strain TDB-1 during growth on different TAP concentration was tested. Figure 5 shows the time-variation of $\mathrm{CSH}$ in $0,100,200 \mathrm{mg} / \mathrm{l}$ TAP, respectively. Without suppling TAP, the MATH increased to $28.2 \%$, but then decreased quickly and remained around $5 \%$. When $100 \mathrm{mg} / \mathrm{l} \mathrm{TAP}$ was added, the MATH increased to a maximum of about $27.2 \%$. And then, a slight increase occurred after a short decrease. After that, the MATH remained constant at around $20 \%$. However, with concomitant increase in the TAP concentration from 100 to $200 \mathrm{mg} / \mathrm{l}$, the maximum hydrophobicity rose to $50.9 \%$, while a decrease occurred after reaching the maximum hydrophobicity. The decrease was just for a short time, and the MATH increased to $34.9 \%$ and kept around $30 \%$. On the whole, the higher the concentration of TAP was, the bigger the MATH of strain TDB-1 was. It coincides with that of Rhodococcus sp. CN6 during growth on $p$-nitrophenol (Zhang et al., 2009). The higher $\mathrm{CSH}$ implied more adherence ability of the pollutants to the cell surface of the biodegrader, so the high $\mathrm{CSH}$ of strain TDB-1can enhance its biodegardation. The CSH is dependent on the constituents of the cell outer membrane, and also is influenced by environment factors (Roseberg et al., 1980). So, further studies of strain TDB-1 would enhance its potential apllication in TAP bioremediation.

\section{ACKNOWLEDGEMENT}

This work was supported by the National Natural Science 


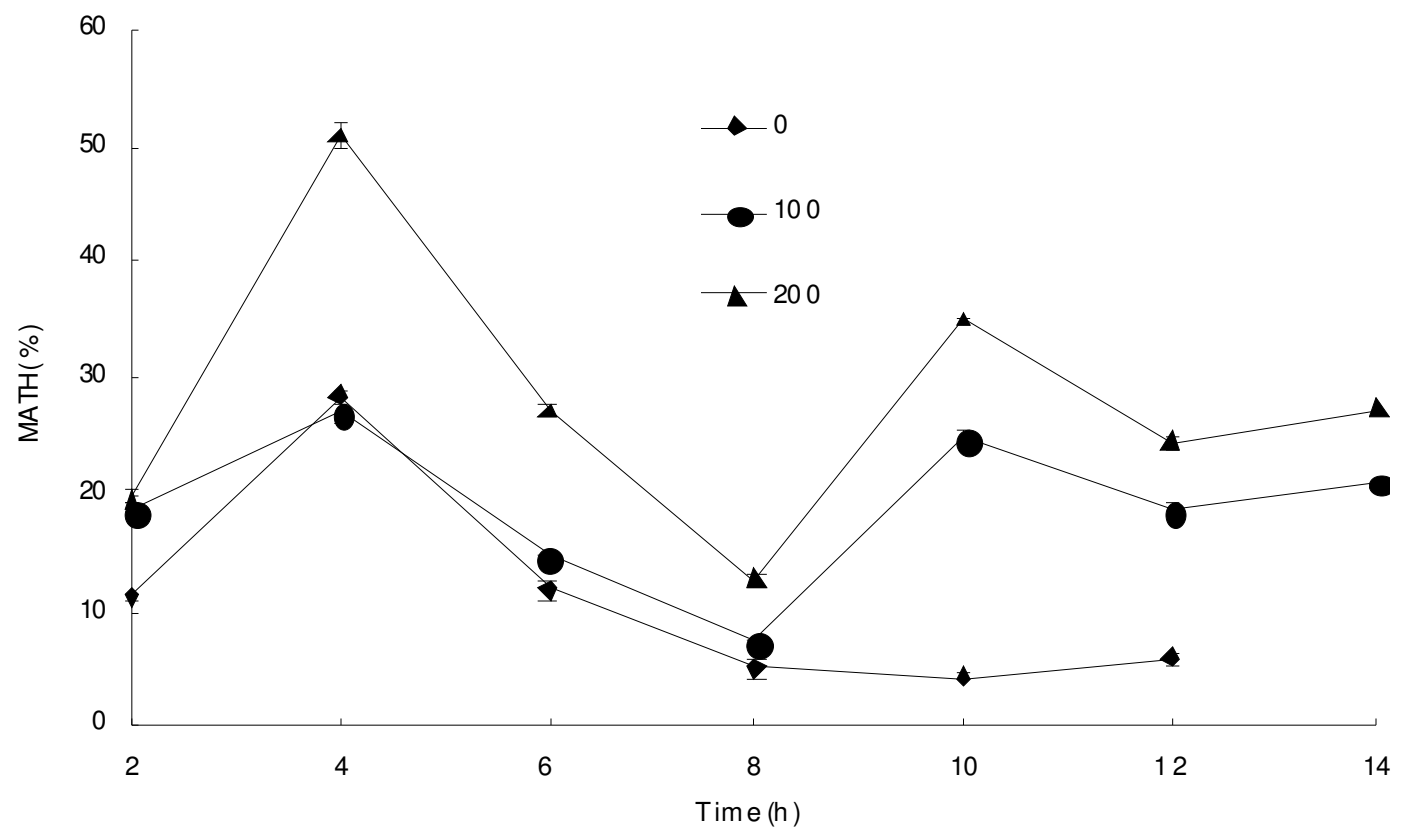

Figure 5. Hydrophobicity (as MATH\%) of strain TDB-1 in degrading different TAP concentration (mg/l).

Foundation of China (31101499, 31071753).

\section{REFERENCES}

Alexis, JH, Li C, lan, CS (2001). Thermal stability of organophosphorus pesticide triazophos and its relevance in the assessment of risk to the consumer of triazophos residues in food. J. Agric. Food Chem. 49: 103-106

Anderson BS, Hunt JW, Phillips BM, Nicely PA, Vlaming de V, Connor V, Richard N, Tjeerdema RS (2003). Integrated assessment of the impacts of agricultural drainwater in the Salinas River (California, USA). Environ. Pollut. 124: 523-532.

Bastiaens L, Springael D, Wattiau P, Harms H, Wachter R, Verachtert H, Diels $L(2000)$. Isolation of adherent polycyclic aromatic hydrocarbon (PAH)-degrading bacteria using PAH-sorbing carriers. Appl. Environ. Microbiol. 66: 1834-1843.

Canganella F, Wiegel J (2011). Extremophiles: from abyssal to terrestrial ecosystems and possibly beyond. Naturwissenschaften 98 : 253-279

Chen SH, Hu MY, Liu JJ, Zhong GH, Yang L, Rizwan-ul-Haq M, Han HT (2011). Biodegradation of beta-cypermethrin and 3-phenoxybenzoic acid by a novel Ochrobactrum lupini DG-S-01. J. Hazard. Mater. 187: 433-440.

Concepción CF, Edgar DG, Alejandra VR, Raunel TV, Rafael DM, Enrique SS, Ma-Luisa CG, Fernando RQ, Laura OH (2012). Isolation of the opdE gene that encodes for a new hydrolase of Enterobacter sp. capable of degrading organophosphorus pesticides. Biodegradation, 23:387-397

Cycoń M, Wójcik M, Piotrowska-Seget Z (2009). Biodegradation of the organophosphorus insecticide diazinon by Serratia $\mathrm{sp}$. and Pseudomonas sp. and their use in bioremediation of contaminated soil. Chemosphere, 76: 494-501.

George, MG, Julia, AB, Timothy GL (1994). Bergey's Manual of Determinative Bacteriology, New York: Springer, pp. 473-476.

Hayes, AL, Wise, RA, Weir, FW (1980). Assessment of occupational exposure to organophosphates in pest control operators. Am. Ind. Hyg. J. 41: 568-575.
Hreljac I, Filipič M (2009). Organophosphorus pesticides enhance the genotoxicity of benzo(a) pyrene by modulating its metabolism. Mutat. Res. 671: 84-92.

Jokanović M, Kosanović M (2010). Neurotoxic effects in patients

poisoned with organophosphorus pesticides, Environ. Toxicol. Pharmacol. 29: 195-201.

Kaloyanova FP, El-Batawi MA (1991). Organophosphorus compounds Human Toxicity of Pesticides. CRC Press, Boca Raton, FL. pp. 3-33.

Li W, Qiu SP, Wu YJ (2008). Triazophos residues and dissipation rates in wheat crops and soil. Ecotoxicol. Environ. Saf. 69:312-316

Lin KD, Yuan DX (2005). Degradation kinetics and products of triazophos in intertidal sediment. J. Environ. Sci. 17: 933-936.

Mearns J, Dunn J, Lees-Haley PR (1994). Psychological effects of organophosphate pesticides: a review call for research by psychologists. J. Clin. Psychol. 50: 286-293.

Rosenberg M, Gutnick D, Rosenberg E (1980). Adherence of bacteria tohydrocarbons: a simple method for measuring cell-surface hydrophobicity. FEMS. Microbiol. Lett. 9: 29-33.

Rovedatti MG, Castañé PM, Topalián ML, Salibián A (2001). Monitoring of organochlorine and organophosphorus pesticides in the water of the Reconquista. River. Wat. Res. 35: 3457-3461.

Sawaya WN, Al-Awadhi, FA, Saeed T, Al-Omair A, Husain A, Ahmad N, Al-Omirah H, Al-Zenki S, Khalafawi S, Al-Otaibi J, Al-Amiri H (2000). Dietary intake of organophosphate pesticides in Kuwait. Food. Chem. 69: 331-338.

Seo JS, Keum YS, Harada RM, Li QX (2007). Isolation and characterization of bacteria capable of degrading polycyclic aromatic hydrocarbons (PAHs) and organophosphorus pesticides from PAH-contaminated soil in Hilo, Hawaii. J. Agric. Food. Chem. 55: 5383-5389

Steven BB, Tara DS, Chip G, John O, Colin S, Michael D (2008). OpdA, a bacterial organophosphorus hydrolase, prevents lethality in rats after poisoning with highly toxic organophosphorus pesticides. Toxicology 247: 88-92.

Tamura K, Peterson D, Peterson N, Stecher G, Nei M, Kumar S (2011). MEGA5: Molecular Evolutionary Genetics Analysis using Maximum Likelihood, Evolutionary Distance, and Maximum Parsimony Methods. Mol. Biol. Evol. 28: 2731-2739. 
Wang LH, Zhang L, Chen HL, Tian QG, Zhu GN (2005). Isolation of a triazophos-degrading strain, Klebsiella sp. E6 effectively utilizing triazophos as sole nitrogen source. FEMS. Microbiol. Lett. 253: 259-265

Yang C, Zhao Q, Liu Z, Li QY, Qiao CL, Mulchandani A, Chen W (2008). Cell Surface Display of Functional Macromolecule Fusions on Escherichia coli for Development of an Autofluorescent Whole-Cell Biocatalyst. Environ. Sci. Technol. 42: 6105-6110

Zhang JS, Sun ZT, Li YY, Peng X, Li W, Yan YC (2009). Biodegradation of $p$-nitrophenol by Rhodococcus sp. CN6 with high cell surface hydrophobicity. J. Hazard. Mater. 163: 723-728.

Zhang SB, Zhang DY, Liu Y, Luo XW, Cheng FX, Luo YH (2009). Isolation, identification and degrading gene cloning of a pyrethroids-degrading bacterium. Acta. Microbiologica. Sinica. 49: 1520-1526.
Zhang ZL, Hong HS, Wang XH, Lin JQ, Chen WQ, Xu L (2002). Determination and load of organophosphorus and organochlorine pesticides at water from Jiulong River Estuary, China. Mar. Pollut. Bull. 45: 397-402. 